\title{
Effect of Family Empowerment on Self Care of Patients with Type-2 Diabetes Mellitus: A Systematic Review
}

\author{
Rianti Pramita (D), Siti Saidah Nasution*(i), Jenny Marlindawani(i) \\ Department of Medical Surgical Nursing, Faculty of Nursing, Universitas Sumatera Utara, Medan, Indonesia
}

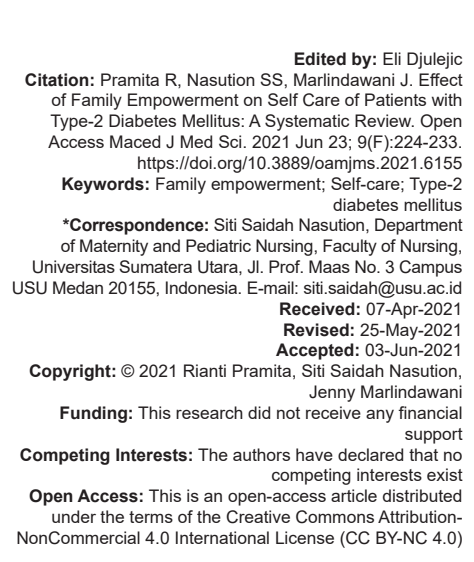

Introduction

Type-2 diabetes mellitus (T2DM) is a disease caused by an absolute and relative insulin deficit so that its impact results in increased plasma glucose levels or hyperglycemia (ADA, 2018). About 422 million people worldwide have diabetes. Of 1.6 million deaths were directly from diabetes occurring each year and another 2.2 million deaths were caused by increasing blood sugar levels. By 2030, it is expected to increase to more than 422 million. The prevalence of diabetes has increased faster in low- and middle-income countries than in high-income countries. Diabetes is the leading cause of blindness, kidney failure, heart attack, stroke, and lower limb amputation [1], [2].

International Diabetes Federation (IDF, 2017) estimates that the prevalence of T2DM disease incidence in all countries is higher than the incidence of T1DM. In 2015-2018, the prevalence rate of T2DM reached 415 million patients from several countries, such as the United States ranged from $10 \%$ to $15 \%$, Caucasians ranged from $4 \%$ to $6 \%$, and $2-4 \%$ in Africa suffered from T2DM. It is estimated that by 2040 the prevalence of T2DM incidence rate will increase by a very high number of approximately 642 million people in the world.

T2DM becomes a chronic disease that will be suffered for life, it is necessary to provide education to patients and families to easily understand the course of disease, prevention, and obstacles in the management of T2DM. Family empowerment can be started by optimizing family functions to help T2DM patients to adapt and adhere to self-care measures through four dimensions, empathy (emotional), encouragement (reward), facilitative (instrumental), and participatory (participation) [3], [4]. Family members are the primary source of instrumental and emotional support. Instrumental supports include helping patient' specific tasks completion, such as making an appointment with a healthcare provider or injecting insulin's, while emotional support can include providing comfort and encouragement when the patient faces pressure or frustration during long-term diabetes treatment [5].

Basically, humans need self-care for themselves, except for people who are unable to treat themselves independently but the need for help from others. Self-care is an activity performed 
by an individual for himself or herself in order to maintain health, life, and well-being. Self-care is a form of behavior that focuses on the participation and responsibility of individuals in disease management. Diabetes self-care is an effort to treat individuals in diabetes control including taking medication and preventing complications. The purpose of self-care is to obtain ideal blood glucose levels [6].

Family empowerment is a nursing intervention used by nurses to assist families in caring for and providing support to family members with chronic diseases that are seen as the most important element for successful treatment. Nurses as health-care providers must not only examine the characteristics of respondents from the knowledge, attitudes, and health-care skills but also examine the family and cultural characteristics that can influence the health assessments. Nursing interventions are not only given to sick individuals but also families who care for them [7]. Family empowerment intervention is expected to be an approach that can be done to improve the self-care activities of people with diabetes mellitus. For the suppression and prevention of diseases for people with diabetes mellitus, and the increasing ability of the family and support the independence of care acceptance, the approach of empowerment and involving the family as a companion is expected to be effective [8].

Some research confirms that using familycentered education and using patterns such as familycentered empowerment can be effectively promoting individual self-care behaviors. Family empowerment improves knowledge and attitudes, leading to improved performance and quality of care, improved self-care, accelerated patient recovery, and reduced complications of disease [9]. Health-care strategies involving family members can improve self-efficacy, knowledge of the disease condition, and self-care skills in individuals with chronic conditions such as T2DM in managing blood glucose levels, maintaining personal hygiene, consuming appropriate food, complying with medications, and maintaining physical activity levels [10]. The results of the study [11] also said that community or family empowerment is one of the effective strategies to improve health status through family engagement with an educational approach. Facilitating the involvement of all family members and communities in assisting individuals and families in decision making, helps families get positive experiences that are in line with expectations, addressing problems in self-care.

Through the writing of this systematic review will be given an overview of the influence of family empowerment programs on improving self-care for T2DM patients. The purpose of writing systematic review is to identify the influence of family empowerment programs conducted on T2DM patients on self-care improvement.

\section{Methods}

Systematic review is essential to accurately and reliably summarize evidence; the selected systematic method can minimize bias thus providing reliable findings. This method of writing a systematic review was carried out and reported in accordance with the guidelines of diagram Preferred Reporting Items for Systematic reviews and Meta-Analyses (PRISMA) and uses analysis of descriptive narratives from the findings of several research articles that discuss the influence of family empowerment on self-care of T2DM patients.

Prisma guidelines focused on ways in which authors could ensure systematic report and transparent review as well as meta-analysis that could help authors report a variety of systematic reviews to assess the benefits and dangers of health-care interventions (Liberati et al., 2009). In addition, the structured approach to facilitate the analysis process of research articles in this systematic review also used PICOS model consisting of population, intervention, comparator, outcome, and study design. PICOS was used to help authors determine inclusion and exclusion criteria so that authors can perform an article filtering process to assess the feasibility of all studies obtained from the database.

\section{Inclusion criteria and exclusion criteria}

\section{Search strategies and search information} resources

The author used an international electronic database consisting of EBSCO, PubMed, and ProQuest as the source of articles in this systematic review with a time span of research articles ranging from 2016 to 2021 (the last 5 years). Article search performed to complete this systematic review used keywords on a database tailored to research topics and titles and used Boolean operators' standard and equivalent words obtained from Medical Heading Subject. Keywords used include "Family Empowerment" OR "Family Support" AND "Self Care” AND “Diabetes Mellitus Type 2."

Table 1: Inclusion and exclusion criteria

\begin{tabular}{|c|c|c|}
\hline No. & Inclusion criteria & Exclusion criteria \\
\hline 1. & $\begin{array}{l}\text { Population in study focuses on T2DM } \\
\text { patients }\end{array}$ & $\begin{array}{l}\text { Population in study is not T2DM } \\
\text { patients }\end{array}$ \\
\hline 2. & $\begin{array}{l}\text { A study that examines the provision of family } \\
\text { empowerment intervention programs with } \\
\text { self-care }\end{array}$ & $\begin{array}{l}\text { A study that does not address family } \\
\text { empowerment interventions that } \\
\text { are not aimed at self-care of T2DM } \\
\text { patients }\end{array}$ \\
\hline 3. & $\begin{array}{l}\text { The control group for other interventions is } \\
\text { not as a comparison, the use of other groups } \\
\text { is only limited to observe without intervention }\end{array}$ & None \\
\hline 4. & $\begin{array}{l}\text { A study that discusses interventions that } \\
\text { affect self-care improvement in T2DM } \\
\text { patients }\end{array}$ & $\begin{array}{l}\text { A study that discusses self-care in } \\
\text { addition to T2DM patients }\end{array}$ \\
\hline 5. & Quasi-experiment and RCT & $\begin{array}{l}\text { Case study, cross-sectional study, } \\
\text { qualitative research, systematic } \\
\text { review, and meta-analysis }\end{array}$ \\
\hline 6. & Research articles published in the period & Research articles published before \\
\hline 7. & $\begin{array}{l}2016-2021 \text { and full text } \\
\text { Articles in English }\end{array}$ & $\begin{array}{l}2016 \text { and not full text } \\
\text { Articles not in English }\end{array}$ \\
\hline
\end{tabular}




\section{Article selection}

The authors performed the process of filtering research articles using the PRISMA method with four stages. The first stage was the identification stage where the author combined all research articles from the search results on the database. The second stage was screening, in this stage the author conducted a selection based on the title of the research article then adjusted to the criteria of inclusion and exclusion criteria that have been set (Table 1), the article was included if it met the inclusion criteria and would be excluded if the article had the requirement of exclusion criteria. The third was the eligibility stage where the author conducted a selection based on abstracts from research articles obtained and adapted to the inclusion criteria. The fourth stage was the including stage, in this stage the author conducted a selection again with full text that was adjusted to the inclusion criteria as well as reviewing the quality of each research article so that at this stage research articles that were completely appropriate and relevant to the topic of research for review or systematic review obtained.

\section{Quality assessment}

Systematic review is essentially an analysis of the available literature (i.e. evidence) and an assessment of effectiveness or practice, involving a complex set of steps. The Joanna Briggs Institute (JBI) guide takes a specific view of what is considered evidence and the methods used to synthesize these types of evidence. In line with the broader view of evidence, the institute has developed rigorous theories, methodologies, and processes for critical assessment and synthesis of these diverse forms of evidence to aid clinical decision making in healthcare. In this systematic review, the assessment of articles used JBI Critical Appraisal guidelines. JBI Critical Appraisal is an instrument used to assess the methodological quality of a study and to determine the extent to which it has discussed possible biases in its design, intervention, and analysis [12], [13]. JBI Critical Appraisal instrument is also adapted to several types of research used, including JBI Critical Appraisal for Randomized controlled trial, JBI Critical Appraisal for quasi-experiment, JBI Critical Appraisal tools for systematic reviews and research syntheses and others [14].

\section{Data extraction}

In the writing of this systematic review, relevant data were extracted to a computer-based spreadsheet. The author filtered the selected information based on PRISMA method with categories consisting of author name, year of publication, publisher's journal, language, country of study, article title, research objectives, population of research, number of respondents, research design, intervention, method, instrument, validity and reliability value, statistical tests, research limitations, and findings of the research as attached to Table 2.

\section{Results}

\section{Search results}

Based on the flowchart for the article search strategy method or PRISMA diagram, at the identification stage there were 2635 articles obtained from several electronic databases with the following details from EBSCO as many as eight articles, PubMed 1985 articles, and ProQuest 640 articles. At the screening stage after the selection, there was a reduction of 46 articles because several article titles from different databases were the same, so that the remaining 2589 articles were then screened based on title and abstract. After screening, 2370 articles were excluded because there were types of research, design, family empowerment interventions, publishing years, and languages that did not meet the inclusion criteria. Furthermore, at the eligibility stage, there were 135 articles that would be reviewed in full text and 127 articles were excluded because they did not match with the population of T2DM patients, did not provide family empowerment interventions, articles were not in English and published before 2016. At the included stage, a full text review and quality assessment of articles was performed so that eight articles that met the inclusion criteria and had the same purpose that was to see the influence of family empowerment interventions on the improvement of self-care T2DM patients.

\section{Research design}

The description of the eight articles in this systematic review consisted of two research designs, namely, seven articles that use RCT research design [7], [10], [16], [17], [19], [20] and one article with quasiexperiment design [15].

\section{Characteristics of respondents}

The total number of research respondents from the eight research articles reviewed was 1203 respondents with DM. The highest number of respondents was found in RCT design articles with 242 respondents [16], [17]. From the ten research articles, it was found that the respondents involved in the study were patients with T2DM, the average age of respondents in the range of 30-70 years, male and female gender, and the level of high school education. The research conducted in eight articles came from several countries, three articles from China, and two 


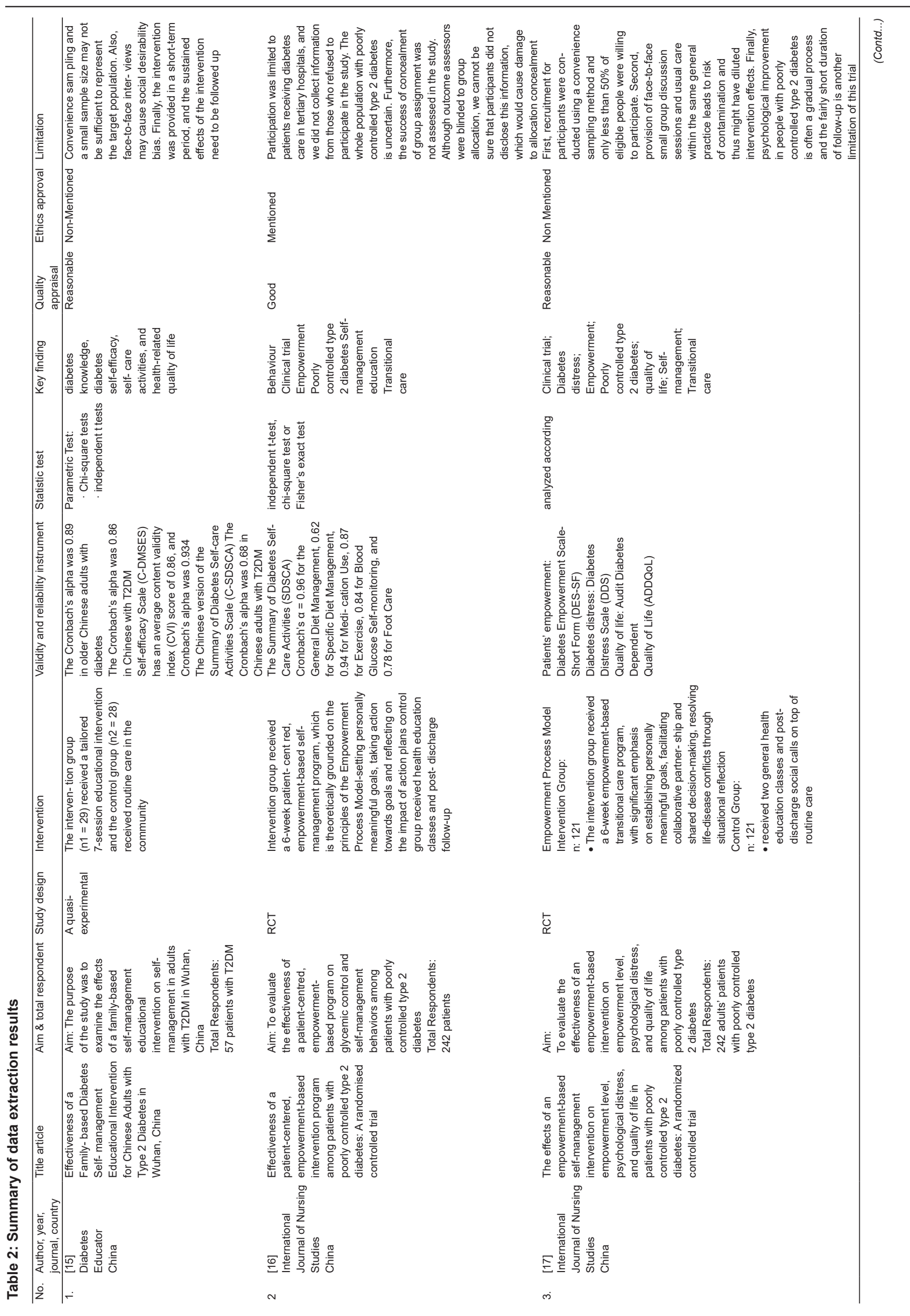

Open Access Maced J Med Sci. 2021 Jun 23; 9(F):224-233. 


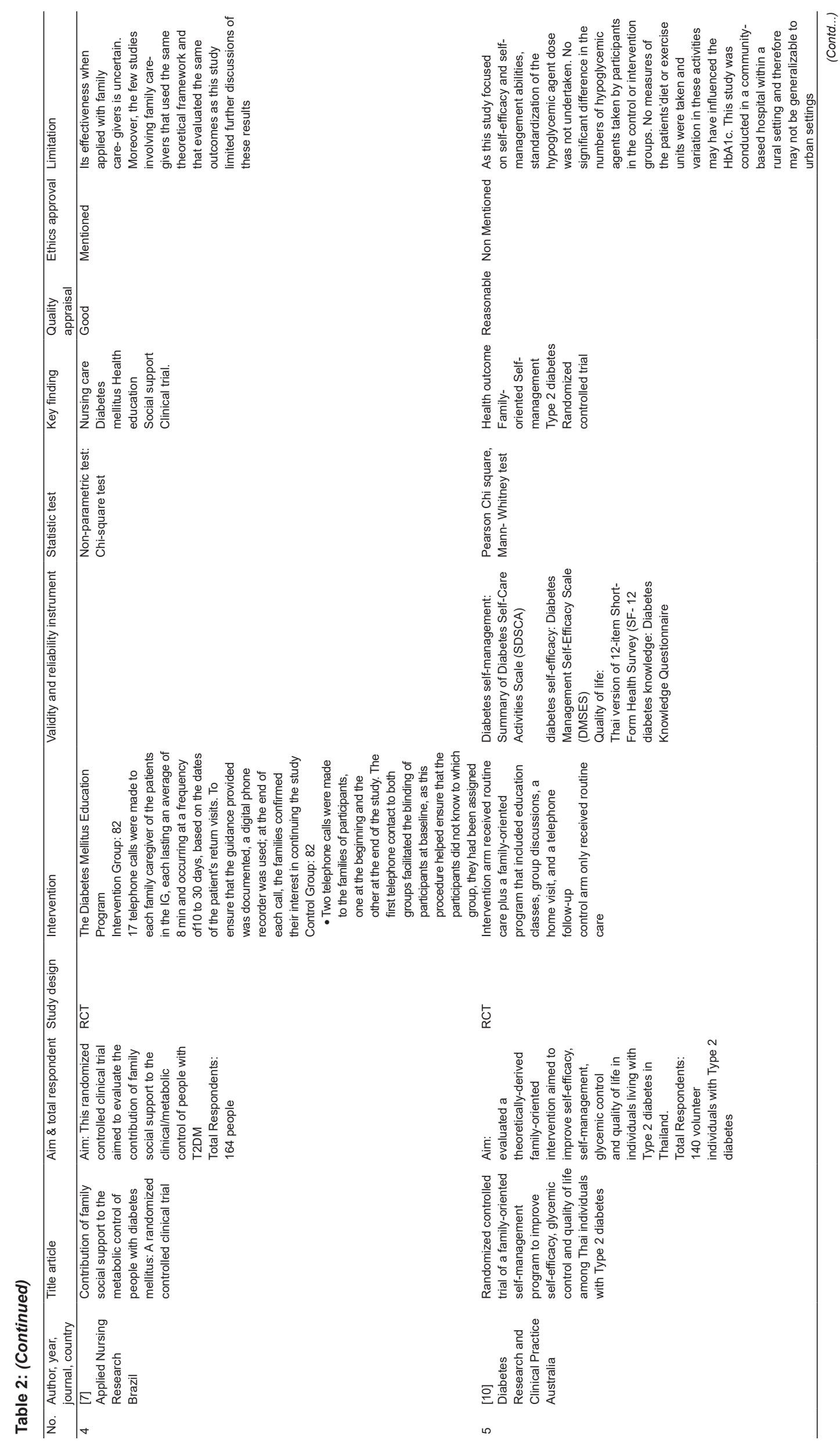




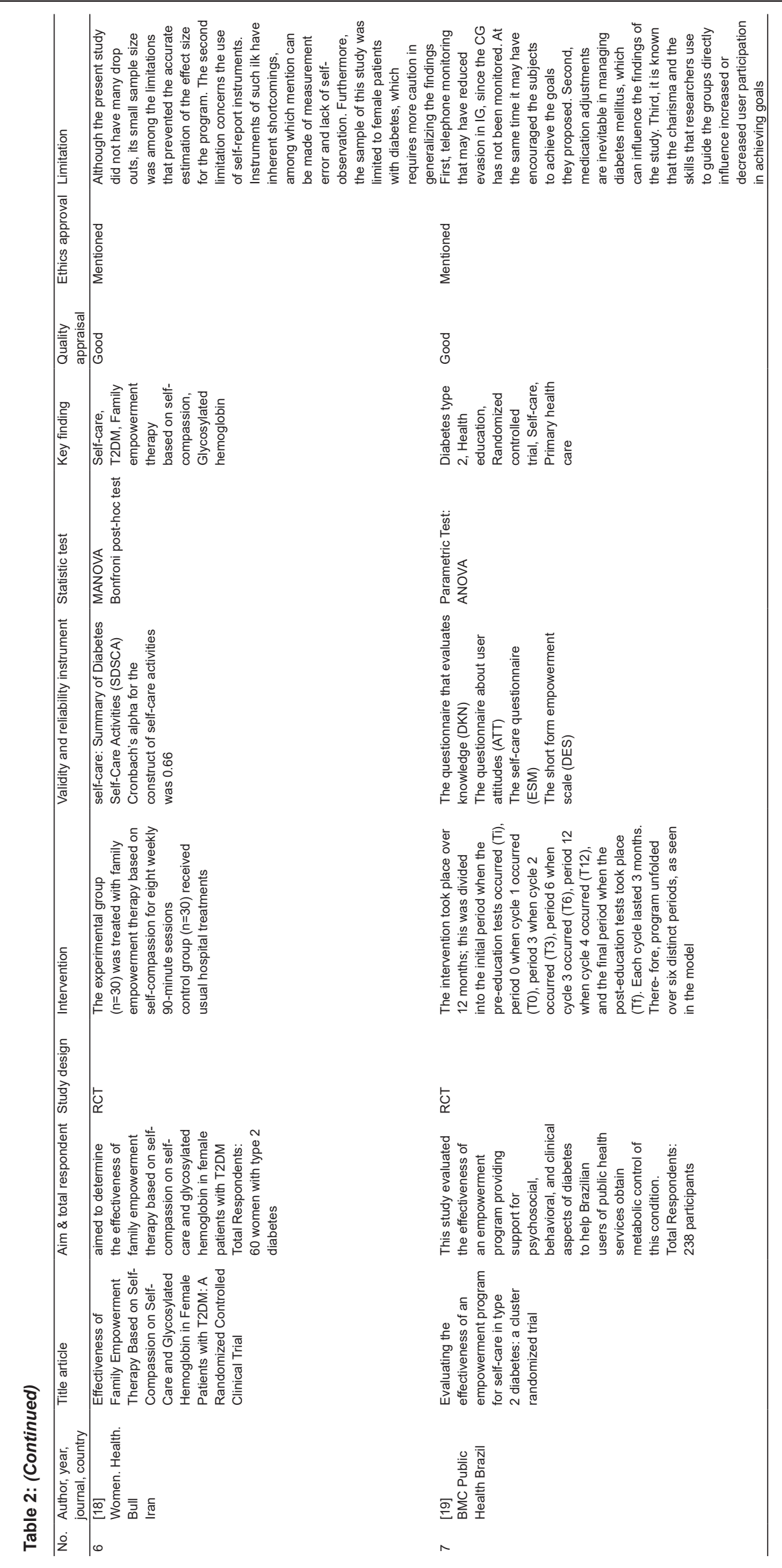

Open Access Maced J Med Sci. 2021 Jun 23; 9(F):224-233. 


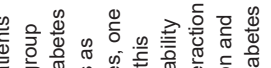

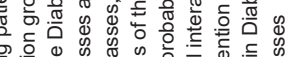

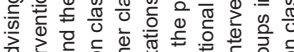

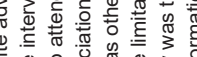

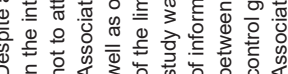

(1)

豙

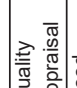

票

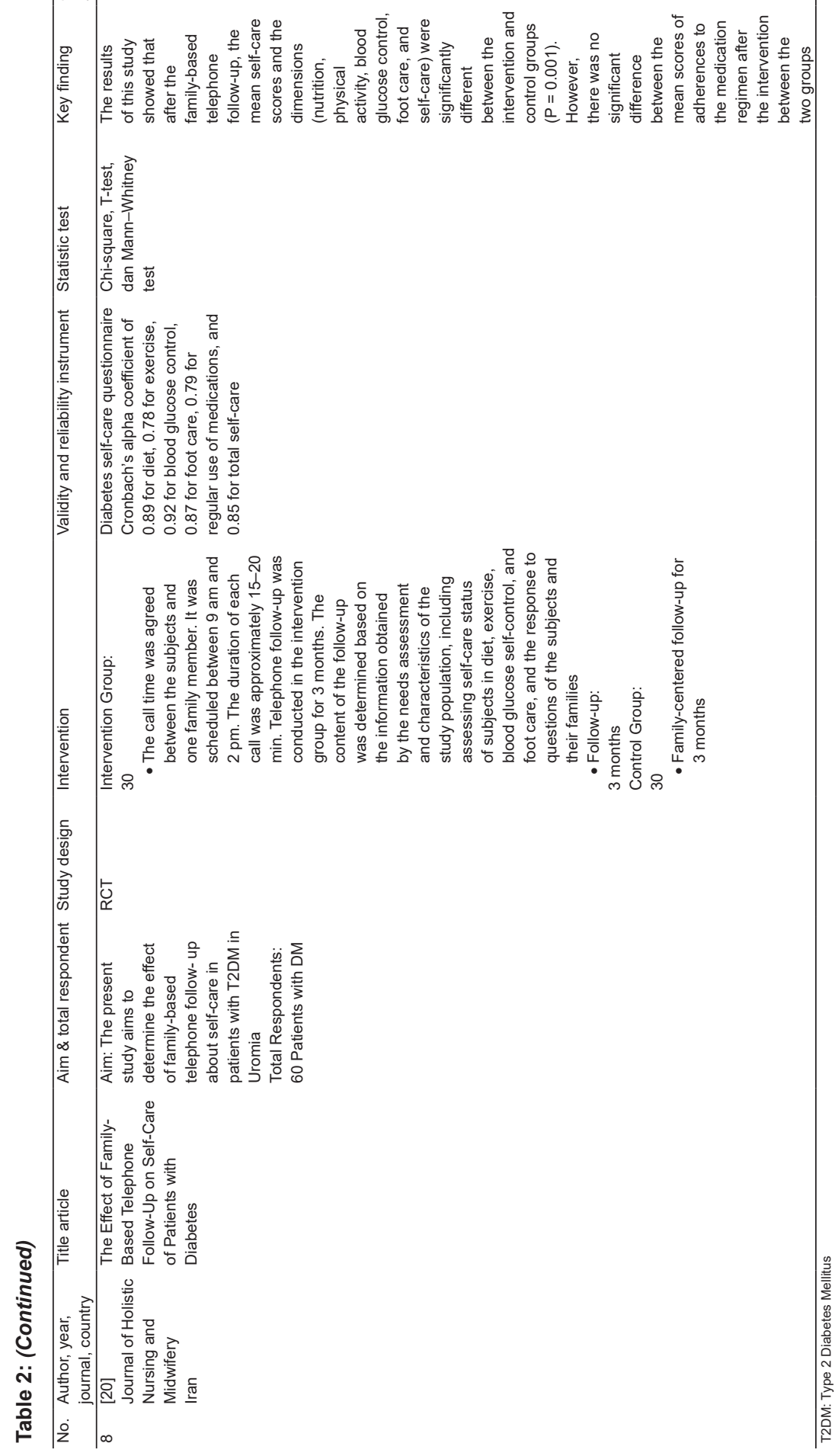


articles each from Brazil, Iran, and one article from Australia.

\section{Characteristics of intervention}

The intervention in eight articles consisted of several types of family empowerment programs given to patients with T2DM as respondents. Family empowerment intervention programs in these eght articles included the Family Empowerment Process Model [16], [17] and the Diabetes Mellitus Education Program [7], [10], [15], [19], [20] which is a familyoriented program that includes educational classes, group discussions, home visits, and follow-up by phone. The call time was agreed between the subject and one family member. That was scheduled between 9 a.m. and 2 p.m. The duration of each call was approximately 15-20 min. Follow-up was done over the phone in the intervention group for approximately 3 months -12 months, while the control group only receive regular treatment as usual. Based on the results of all studies from the intervention program, it showed that the intervention program of Family Empowerment Process Model and Diabetes Mellitus Education Program significantly affected the self-care of patients with T2DM.

\section{Result of methodological quality assessment}

Quality assessment result of the research article is shown in Table 3 above, where from seven articles with RCT design, five articles have good quality [7], [16], [18], [20]. Of the 13 questions, 11 were answered with Yes and two questions with No answers. Two other articles with RCT designs had sufficient quality [10], [17]. Of the 13 questions, nine answered with Yes and four answered with No. As for research articles with quasi-experiment design, there was one article with good quality [15] where of nine questions, all answers were Yes. From the quality assessment results of the research article, the risk of bias that occurs from writing this systematic review can be minimized.

Table 3: The result of article assessment for systematic review using JBI critical appraisal tools

\begin{tabular}{|c|c|c|c|c|c|c|c|c|c|c|c|c|c|c|}
\hline \multirow[t]{2}{*}{ Citations } & \multicolumn{13}{|c|}{ Criteria } & \multirow{2}{*}{ Result } \\
\hline & 1 & 2 & 3 & 4 & 5 & 6 & 7 & 8 & 9 & & 10 & 11 & 1213 & \\
\hline \multicolumn{15}{|l|}{ RCT: } \\
\hline [20] & $\sqrt{ }$ & $\sqrt{ }$ & $\sqrt{ }$ & $\sqrt{ }$ & & $\sqrt{ }$ & $\sqrt{ }$ & $\sqrt{ }$ & 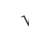 & & $\sqrt{ }$ & $\sqrt{ }$ & $\sqrt{ }$ & $11 / 13(69.2 \%)$ (Good) \\
\hline [17] & $\sqrt{ }$ & $\sqrt{ }$ & $\sqrt{ }$ & & & & $\sqrt{ }$ & $\sqrt{ }$ & 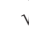 & & $\sqrt{ }$ & $\sqrt{ }$ & $\sqrt{ }$ & 9/13 (69.2\%) (Reasonable) \\
\hline [7] & $\sqrt{ }$ & $\sqrt{ }$ & $\sqrt{ }$ & $\sqrt{ }$ & $\sqrt{ }$ & $\sqrt{ }$ & $\sqrt{ }$ & $\sqrt{ }$ & 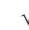 & & $\sqrt{ }$ & $\sqrt{ }$ & $\sqrt{ }$ & $12 / 13(92.3 \%)$ (Good) \\
\hline [10] & $\sqrt{ }$ & $\sqrt{ }$ & $\sqrt{ }$ & & & & $\sqrt{ }$ & $\sqrt{ }$ & 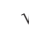 & & $\sqrt{ }$ & $\sqrt{ }$ & $\sqrt{ }$ & 9/13 (69.2\%) (Reasonable) \\
\hline [19] & $\sqrt{ }$ & $\sqrt{ }$ & $\sqrt{ }$ & $\sqrt{ }$ & & $\sqrt{ }$ & $\sqrt{ }$ & $\sqrt{ }$ & 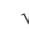 & & $\sqrt{ }$ & $\sqrt{ }$ & $\sqrt{ }$ & $11 / 13(84.6 \%)$ (Good) \\
\hline [19] & $\sqrt{ }$ & $\sqrt{ }$ & $\sqrt{ }$ & $\sqrt{ }$ & & $\sqrt{ }$ & $\sqrt{ }$ & $\checkmark$ & v & & $\sqrt{ }$ & $\sqrt{ }$ & $\sqrt{ }$ & $11 / 13(69.2 \%)$ (Good) \\
\hline [16] & $\sqrt{ }$ & $\sqrt{ }$ & $\sqrt{ }$ & $\sqrt{ }$ & & $\sqrt{ }$ & $\sqrt{ }$ & $\sqrt{ }$ & 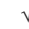 & & $\sqrt{ }$ & $\sqrt{ }$ & $\sqrt{ }$ & $11 / 13(69.2 \%)$ (Good) \\
\hline \multicolumn{15}{|c|}{ Quasy-experiment } \\
\hline [15] & $\sqrt{ }$ & $\sqrt{ }$ & $\sqrt{ }$ & $\sqrt{ }$ & $\sqrt{ }$ & $\sqrt{ }$ & $\sqrt{ }$ & $\sqrt{ }$ & $\sqrt{ }$ & & & & & 9/9 (100\%) (Good) \\
\hline
\end{tabular}

\section{Additional results}

From the eight research articles listed in this systematic review, there were several research articles that not only assessed self-care but also discussed and assessed other results, including assessing quality of life, glycemic control, foot care, and nutrition [15], [17], [20].

\section{Risk of bias}

There are three ways of assessing the risk of bias namely individual components, checked list and scale Liberati et al., (2009). Scale and checklist are rarely used because they are considered to potentially cause a lot of consideration and error. Assessing the risk of bias with the approach of individual components is more recommended because it is based on a domain that has empirical evidence and strong clinical reasons. Therefore, the risk of bias in writing this systematic review is carried out by determining the extraction of data conducted by the authors from the research article findings both in terms of methods, objectives and outcomes resulting from research as well as from the assessment of the quality of research articles. Of the eight articles in this systematic review, there is still a tendency for the risk of bias because of some research articles, especially in articles with RCT design that has not included blinding techniques in the article.

\section{Discussion}

The interventions from eight articles in this systematic review obtained family empowerment

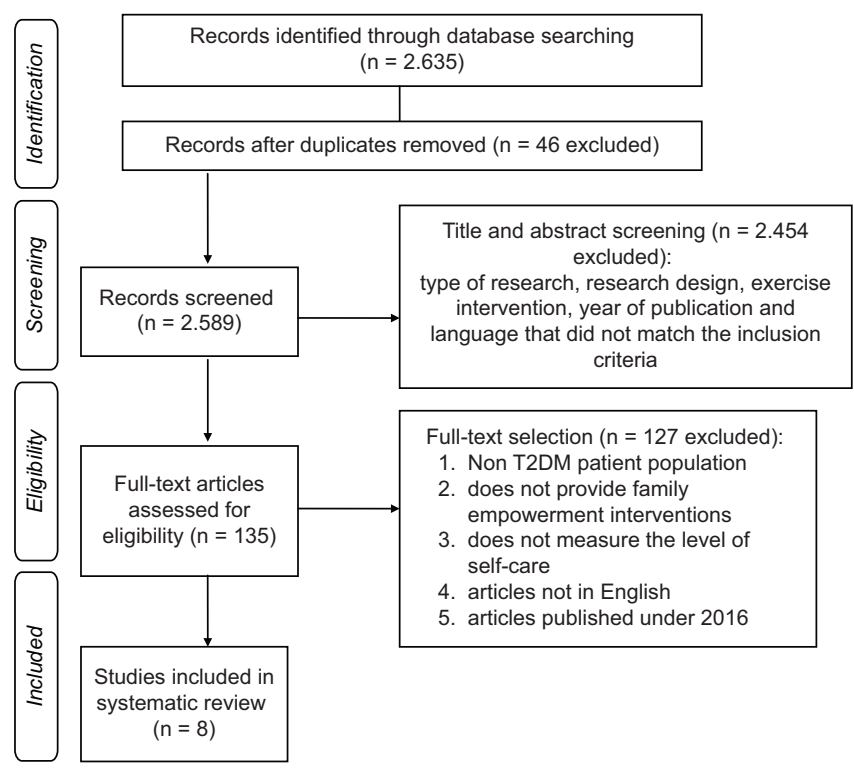

Figure 1: Preferred reporting items for systematic reviews and metaanalyses flow diagram of identification and selection of articles 
intervention programs including the Family Empowerment Process Model program [16], [17] and Diabetes Mellitus Education Program [7], [10], [15], [17], [19], [20]. Based on the results of the article research listed in this systematic review, the intervention was a family-oriented program that included health education, group discussions, home visits, and follow-ups by phone. Education was given to families through live discussions and by phone calls with a duration of approximately 15-20 min scheduled from 9 a.m. to 12 p.m. Follow-up was done over the phone in the intervention group for approximately 3 months-12 months. According to Razmara et al., (2018), family-oriented intervention programs provided by nurses contribute an effective influence on selfcare and its dimensions such as (nutrition, physical activity, blood glucose control, and foot care) in diabetic patients [20]. Therefore, nurses are advised to follow-up and make family empowerment programs through education by educating family members of patients to participate in diabetes treatment.

Family empowerment program based on health education related to disease care is one of the intervention programs used by nurses to help families in caring for and providing support to family members with chronic diseases. Nursing interventions are not only given to sick individuals, but also families who care for them [7]. Family empowerment intervention is expected to be an approach that can be done to increase selfcare activities of people with diabetes mellitus [8]. The research results of Rahmani et al., (2020) also said that compassion-based family empowerment therapy with affection in providing care to family members suffering from DM can provide an effective influence in improving self-care and lowering glycosylated hemoglobin in women with type-2 diabetes [18]. According to Al et al., (2021), self-care is one of the important aspects in the treatment of patients with chronic diseases. Applying a family-centered empowerment model to patients by strengthening the care capabilities of patients and their families are significantly able to improve the patients' quality of life for the better [21].

There are several studies using the Summary of Diabetes Self Care Activities measuring instruments that have 14 question items. The questionnaire consisted of 12 favorable items [1], [2], [3], [4], [7], [8], [9], [10], [11], [12], [13], [14] and two unfavorable items (5 and 6). The lowest possible score is 14 and the highest score is 98 . The higher the number of scores, the better the self-care behavior of T2DM patients. The assessment range in this questionnaire is 84 which is divided into assessment categories namely: 70-98= Good, 42-69= Fair, 14-41= Poor. It is continued with the provision of family empowerment interventions by providing education related to family empowerment interventions [10], [15], [16], [18].

This systematic review still has some limitations. In eight studies that had been reviewed, among others, the use of RCT design that has not used blinding technique in the study and follow-up time for self-care measurement that is still considered too short in just 3 months.

\section{Further research advice}

The findings of several studies in this systematic review indicate the need for further research. Applying blinding techniques as well as the use of control groups or by comparison interventions need to be conducted to strengthen the results of the study and observe more effective intervention programs to be applied. In addition, researchers also need to pay attention to other factors that contribute to influence self-care in T2DM patients.

\section{Implications for practice}

The findings obtained in this systematic review can support the implementation of intervention programs empowering patients' families by nurses in conducting self-care specifically when the patient has returned home. The implementation of this intervention program can be done in hospitals when the patient is inpatient or outpatient.

\section{Conclusion}

Physical exercise intervention programs of eight studies in this systematic review provide significant results on increasing self-careforT2DM patients, this systematic review can be used as reliable evidence in providing family empowerment intervention programs for the improvement of self-care for T2DM patients.

\section{Acknowledgment}

The author would like to thank to DR. Muryanto Amin as Rector Universitas Sumatera Utara and to DR. Dudut Tanjung as Dean Faculty of Nursing, Universitas Sumatera Utara.

\section{Authors Contribution}

Rianti Pramita: Compiling and conducting systematic reviews and writing manuscripts Siti Saidah Nasution and Jenny Marlindawani Purba: Conducting 
guidance and contributing important intellectual content during the process of drafting and revising manuscripts.

\section{References}

1. American Diabetes Association. Updates to the standards of medical care in diabetes-2018. Diabetes Care. 2018;41(9):20457. https://doi.org/10.2337/dc18-su09

PMid:30135199

2. World Health Organization. Diabetes Mellitus. Geneva: World Health Organization; 2021. Available from: https://www.who. int/news-room/fact-sheets/detail/diabetes. [Last accesseed on 2021 Mar 17].

3. Karuranga S, Fernandes J, Huang Y, Malanda B. IDF Diabetes Atlas. $8^{\text {th }}$ ed. Belgium: International Diabetes Federation; 2017.

4. McEwen MM, Pasvogel A, Murdaugh C, Hepworth J. Effects of a family-based diabetes intervention on behavioral and biological outcomes for mexican american adults. Diabetes Educ. 2017;43(3):272-85. https://doi.org/10.1177/0145721717706031 PMid:28447545

5. Baig AA, Benitez A, Quinn MT, Burnet DL. Family interventions to improve diabetes outcomes for adults. Ann N Y Acad Sci. 2015;1353(1):89-112. https://doi.org/10.1111/nyas.12844 PMid:26250784

6. Amelia R, Lelo A, Lindarto D, Mutiara E. Analysis of factors affecting the self-care behaviors of diabetes mellitus Type 2 patients in Binjai, North Sumatera-Indonesia. Asian J Microbiol Biotechnol Environ Sci. 2018;20(2):361-7.

7. Gomes LC, Coelho AC, Dos Santos Gomides D, FossFreitas MC, Foss MC, Pace AE. Contribution of family social support to the metabolic control of people with diabetes mellitus: A randomized controlled clinical trial. Appl Nurs Res. 2017;36:68-76. https://doi.org/10.1016/j.apnr.2017.05.009

\section{PMid:28720242}

8. Sakanashi S, Fujita K. Empowerment of family caregivers of adults and elderly persons: A concept analysis. Int J Nurs Pract. 2017;23(5):1-9. https://doi.org/10.1111/ijn.12573

\section{PMid:28691266}

9. Sürücü HA, Büyükkaya Besen $D$, Erbil EY. Empowerment and social support as predictors of self-care behaviors and glycemic control in individuals with Type 2 diabetes. Clin Nurs Res. 2018;27(4):395-413. https://doi. org/10.1177/1054773816688940

\section{PMid:28132513}

10. Wichit N, Mnatzaganian G, Courtney M, Schulz P, Johnson M Randomized controlled trial of a family-oriented selfmanagement program to improve self-efficacy, glycemic control and quality of life among Thai individuals with Type 2 diabetes. Diabetes Res Clin Pract. 2017;123:37-48. https://doi. org/10.1016/j.diabres.2016.11.013

PMid:27918976

11. Nasution SS, Erniyati E. The intervention of community role for improving health status of pregnant women suffering HIV-AIDS in medan. Open Access Maced J Med Sci. 2018;6(9):1768-72. https://doi.org/10.3889/oamjms.2018.324 PMid:30338005

12. Moher D, Liberati A, Tetzlaff J, Altman DG, Altman D, Antes $G$, et al. Preferred reporting items for systematic reviews and meta-analyses: The PRISMA statement. PLoS Med. 2009;6(7):e1000097. https://doi.org/10.1371/journal. pmed.1000097 PMid:19621072

13. The Joanna Briggs Institute. Checklist for Quasi-Experimental Studies. Australia: Joanna Briggs Institute; 2017. p. 1-7.

14. The Joanna Briggs Institute. Checklist for Systematic Reviews and Research Syntheses. Australia: Joanna Briggs Institute; 2017.

15. Cai C, Hu J. Effectiveness of a family-based diabetes selfmanagement educational intervention for chinese adults with Type2 diabetes in Wuhan, China. Diabetes Educ. 2016;42(6):697711. https://doi.org/10.1177/0145721716674325 PMid:27831523

16. Cheng L, Sit JW, Choi KC, Chair SY, Li X, Wu Y, et al Effectiveness of a patient-centred, empowerment-based intervention programme among patients with poorly controlled Type 2 diabetes: A randomised controlled trial. Int J Nurs Stud. 2018;79(74):43-51. https://doi.org/10.1016/j. ijnurstu.2017.10.021

PMid:29149618

17. Cheng L, Sit JW, Choi KC, Chair SY, Li X, Wu Y, et al. The effects of an empowerment-based self-management intervention on empowerment level, psychological distress, and quality of life in patients with poorly controlled Type 2 diabetes: A randomized controlled trial. Int J Nurs Stud. 2019;3(21):1-8. https://doi. org/10.1016/j.ijnurstu.2019.103407

18. Rahmani S, Mansoobifar M, Sirifi MR, Ashayeri H, Bermas $H$. Effectiveness of family empowerment therapy based on selfcompassion on self-care and glycosylated hemoglobin in female patients with Type 2 diabetes mellitus: A randomized controlled clinical trial. Womens Health Bull. 2020;7(2):33-42.

19. Cortez DN, Macedo MM, Souza DA, Dos Santos JC, Afonso GS, Reis IA, et al. Evaluating the effectiveness of an empowerment program for self-care in Type 2 diabetes: A cluster randomized trial. BMC Public Health. 2017;17(1):41. https://doi.org/10.1186/ s12889-016-3937-5

PMid:28061840

20. Iranagh SR, Hemmati Maslakpak M. The effect of family-based telephone follow-up on self-care of patients with diabetes. J Holist Nurs Midwifery. 2018;28(1):84-91.

21. Al Hoda Taheri B, Salar A. The Effect of Family Empowerment Model on Self-care in Hemodialysis Patients of Zahedan, Iran. Health Scope. 2021;10(1):1-6. https://doi.org/10.5812/ jhealthscope.90951 